\title{
European Loans and Visits System (ELViS) as a Use Case for a Collection Descriptions Standard
}

\author{
Sharif Islam $\ddagger$
}

‡ Naturalis Biodiversity Center, Leiden, Netherlands

Corresponding author: Sharif Islam (sharif.islam@naturalis.nl)

Received: 02 Oct 2020 | Published: 07 Oct 2020

Citation: Islam S (2020) European Loans and Visits System (ELViS) as a Use Case for a Collection Descriptions Standard . Biodiversity Information Science and Standards 4: e59253. https://doi.org/10.3897/biss.4.59253

\section{Abstract}

The European Loans and Visits System (ELViS) is an e-service in development designed to improve access to natural history collections across Europe. Bringing together heterogeneous datasets about institutions, people, collections and specimens, ELViS will provide an e-service (with application programming interfaces (APIs) and portal) that handles various stages of collections-based research. One of the main functionalities of ELViS is to facilitate loan and visit requests related to collections. To facilitate activities such as searching for collections, requesting loans, generating reports on collection usage, and ensuring interoperability with existing and new systems and services, ELViS must use a standard way of describing collections.

In this talk, I show how ELViS can use the Collection Descriptions (CD) standard currently being developed by the CD Task Group at TDWG. I will provide a brief introduction to ELViS, summarise the current development efforts, and show how the Collection Description standard can support specific user requirements (gathered via an extensive set of user stories). I will also provide insight into the data elements within ELViS (see Fig. 1) and how they relate to the Collection Description data model. 


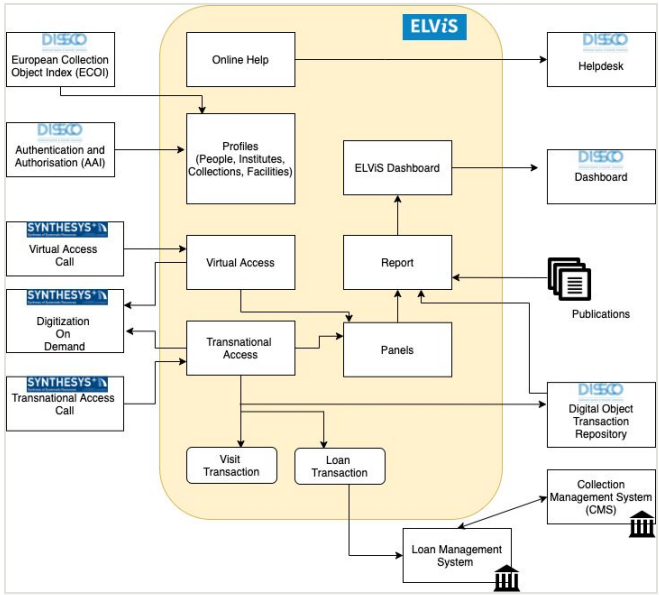

Figure 1.

A high-level conceptual overview of ELViS.

\section{Keywords}

natural science collections, dissco, collections-based research, specimens, collection descriptions

\section{Presenting author}

Sharif Islam

\section{Presented at}

TDWG 2020

\section{Funding program}

H2020-INFRAIA-2018-2020

\section{Grant title}

